Feminism and citizenship. Beyond social citizenship with gender perspective

\title{
Feminismo y ciudadanía. Más allá de la ciudadanía social con perspectiva de género
}

\author{
Nicole Darat G. \\ Universidad Adolfo Ibáñez. \\ nicole_darat@yahoo.es
}

DOI: https://doi.org/10.15366/bp2019.22.008

Bajo Palabra. II Época. № 22. Pgs: 171-188

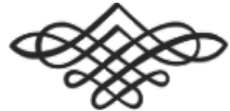


Recibido: 02/08/2018

Aprobado: 02/10/2018

\section{Resumen}

El presente trabajo busca indagar las relaciones entre feminismo y ciudadanía, a partir de la constatación de que la ciudadanía ha sido una categoría política formulada desde de la exclusión de las mujeres en cuanto sujetos políticos. Dicha constatación fuerza a la teoría feminista ya sea a renunciar al concepto de ciudadanía, o a repensarlo radicalmente. El texto propone un análisis de las posibilidades de la segunda opción a partir de una crítica, tanto al liberalismo, como al republicanismo. La ciudadanía feminista se entiende, de este modo, como algo más que la inclusión de las mujeres en la ciudadanía social.

Palabras clave: feminismo, ciudadanía, republicanismo, liberalismo, espacio público.

\section{Abstract}

The following work seeks to inquire the links between feminism and citizenship, starting from the realisation that citizenship is a political category formulated from the exclusion of women as political subjects. That realisation forces feminist theory to either abandon the notion of citizenship or radically transform it. The text proposes an analysis of the possibilities of the second option, from a critique to both liberalism and republicanism. Feminist citizenship can thus be understood as something else than the mere inclusion of women in social citizenship.

Keywords: feminism, citizenship, liberalism, republicanism, public space. 
simple vista parece que el concepto de ciudadanía es poco apropiado para $A$ darle forma a las aspiraciones políticas del feminismo, precisamente porque 1 la ciudadanía, en tanto que categoría legal y estatus, así como en tanto que 'forma de identidad sociopolítica' ${ }^{1}$ se ha construido a partir de la exclusión de las mujeres, los esclavos, los no propietarios y los extranjeros, todos a la vez o con distintas combinaciones, por razones semejantes: su incapacidad para la virtud o para la racionalidad que requiere hacerse cargo de los asuntos públicos.

La historia lineal del desarrollo de la ciudadanía, reconstruida por Marshall en su texto Ciudadanía y clase social $^{2}$, que se ha convertido en el canon a la hora de hablar de ciudadanía, no toma en cuenta la historia de las mujeres ${ }^{3}$, ni de las negras, latinas, migrantes, etcétera, quienes no han logrado acceder plenamente al ejercicio de ninguno de estos derechos.

Por otro lado, la delimitación de la acción propiamente política dentro de los límites de lo que tradicionalmente se denomina sociedad civil, que va de la mano con la teoría mainstream de la ciudadanía, le quita el reconocimiento a acciones y formas de organización de base que suelen ser las más utilizadas por las mujeres pobres y otros grupos excluidos, negando su cualidad de ejercicio de la ciudadanía e identificándolas como acciones subversivas. Siguiendo a Faranak Miraftab ${ }^{4}$, los colectivos en desventaja siempre se han comprometido en acciones políticas consideradas informales, las que a la luz de la crítica feminista de la ciudadanía, pueden aparecer como propiamente políticas, si bien reconoce la necesidad de dedicar más atención a dichas prácticas informales. Con Miraftab, entendemos que el potencial de una teoría y una práctica feminista de la ciudadanía, permite entender como políticas, prácticas que de otro modo serían excluidas. Un concepto feminista de ciudadanía, implica entender como parte de ella las prácticas de resistencia que apuntan a la expansión de los derechos políticos, civiles y sociales y no solo la consolidación de la existencia formal de lo mismos.

${ }^{1}$ Heater, Derek Benjamin, Ciudadania: una breve historia (Madrid: Alianza, 2007).

2 Marshall, T. H. "Citiznship and Social Class." In Inequality and Society, edited by Jeff Manza and Michael Sauder, 148-54. New York: Norton, 2009.

3 Fraser, Nancy, y Linda Gordon. "Contract vs. Charity. Why Is There No Social Citizenship in the United States?" Socialist Review, 1992.

${ }^{4}$ Miraftab, Faranak. «Invited and Invented Spaces of Participation: Neoliberal Citizenship and Feminists' Expanded Notion of Politics». Wagadu 1, n. ${ }^{\circ}$ Spring 2004: 1-7. 
Pretendemos identificar el modelo feminista como un modelo crítico de las categorías políticas de los modelos tradicionales, pues evidencia la incapacidad, tanto del liberalismo, como del republicanismo, para dar cuenta de nuevas prácticas políticas que exceden el concepto de participación tal como estos modelos lo han entendido y que a su vez replantean el concepto mismo de espacio público.

De manera sintética podemos señalar que el liberalismo es una doctrina negativa, es decir, una teoría política que surge desde la oposición a otra, en este caso, al absolutismo ${ }^{5}$. Esta idea se corresponde con el surgimiento histórico del liberalismo y puede constatarse en el pensamiento de sus precursores como Locke, pero también en las figuras propiamente liberales como Tocqueville o Mill quienes desde la desconfianza frente a la "tiranía de la mayoría" ya fuera a través de las instituciones, como de la vigilancia ejercida por la propia sociedad, subrayarán que la libertad política de la que se goce no depende tanto del origen del poder, sino de cómo este se ejerza.

El modelo de sujeto político para el liberalismo, es el sujeto contratante de las teorías del contrato social: un sujeto concebido como carente de relaciones previas, o lo que en palabras de Hobbes sería "como si hubiesen surgido recién de la tierra como hongos y sin ninguna obligación hacia los otros" ${ }^{6}$. Siendo Hobbes un defensor del absolutismo, su comprensión restringida de la libertad y su idea poco exigente de lo que cuenta como consentimiento, se encuentran a la base de la idea de libertad negativa que, de acuerdo con la famosa conceptualización de Berlin ${ }^{7}$, es la que el liberalismo ha hecho propia.

Desde la perspectiva de Carole Pateman ${ }^{8}$, toda la teoría del contrato social está erigida sobre un contrato sexual, mediante el cual los varones adultos pactan entre sí el reparto pacífico de las mujeres y el fin de la regla del padre, que en términos psicoanalíticos aludía al monopolio de las mujeres por parte de este. Este dominio simbólico encuentra su reflejo en la refutación del argumento naturalista del origen de la obligación política, que tiene su momento más sobresaliente en el argumento de Locke para rechazar la tesis expuesta por Sir Robert Filmer en El patriarca, en su Primer tratado sobre el gobierno civil. Para Pateman, dicha refutación que cambia el poder del padre, al cual los hijos están sujetos desde el nacimiento, por el contrato entre individuos libres, solo libera a los varones a cuya medida está diseñado el concepto de individuo, sujeto del contrato social. Los contratantes en el relato loc-

\footnotetext{
5 Macedo, Stephen, Liberal Virtues: Citizenship, Virtue, and Community in Liberal Constitutionalism (Oxford: Clarendon Press, 1992).

${ }^{6}$ Hobbes, Thomas On the Citizen (Cambridge: Cambridge University Press, 1998), Cap. VIII, 10.

7 Berlin, Isaiah, Cuatro Ensayos Sobre La Libertad, El libro universitario (Madrid: Alianza, 1998).

8 Pateman, Carole, The Sexual Contract (Stanford University Press, 1988).
} 
keano son dueños de su cuerpo y es por ello que pueden ser individuos. Las mujeres no gozan de esa propiedad, ellas mismas son propiedad de los varones, lo que les permite a esto asegurar la propiedad sobre los hijos. Para Pateman "El contrato está lejos de oponerse al patriarcado; el contrato es el medio a través del cual el patriarcado moderno es constituido" "Simbólicamente las mujeres teníamos más poder en el estado de naturaleza que en la sociedad civil, a todas luces resultado de un contrato impuesto por la fuerza que se parece más a la obligación política obtenida mediante la conquista, que a la resultante de un pacto mutuamente ventajoso.

La famosa consigna de lo personal es politico, que suele atribuírsele a Kate Millet, por su parte, pone en tela de juicio la división entre lo público y lo privado como dos esferas discretas, desde la cual se yergue la teoría liberal para construir su noción de individualidad y blindar un espacio frente a la intromisión del Estado y de la sociedad. El liberalismo, trastocando los valores clásicos que posicionaban lo púbico como el espacio de la acción propiamente humana, pondrá todas sus cartas en juego en el espacio privado como aquel espacio en que es posible el pleno desarrollo de la individualidad ${ }^{10}$, para las mujeres, en tanto, el espacio privado ha sido el sitio al cual se nos ha confinado y en el cual, en nombre de la privacidad y del derecho de propiedad, hemos sido reducidas a la condición de menos que un sujeto.

La visión liberal enfrentada a la visión republicana del par público/privado, son las dos caras de la moneda de la ciudadanía. Para el liberalismo el ámbito privado aparece como una esfera de autorealización, depositaria del sentido de la vida y frente a la cual, tanto el Estado, como la sociedad deben retroceder. Cualquier demanda de compromiso cívico, solo puede justificarse a partir de los réditos que este le dé al individuo para sus proyectos privados ${ }^{11}$.

El discurso del feminismo liberal puede ser fácilmente reconocido en tanto reivindicará la inclusión de las mujeres en el orden de lo público y su igualación en el acceso a la propiedad en el ámbito privado. Dicho en términos marshallianos, el feminismo liberal circunscribe sus demandas al ámbito civil y político, dejando de lado aquellos derechos que se corresponden con la llamada ciudadanía social. No obstante, es importante no ignorar que, así como existe una bien conocida crítica feminista a la teoría política liberal, existe también, un potente y fructífero feminismo liberal. El llamado "feminismo de la primera ola" o "movimiento por los derechos de las mujeres", estaba, tal como lo indica su nombre, enfocado en las de-

\footnotetext{
9 Pateman, Carole The Sexual Contract (Stanford University Press, 1988).

${ }^{10}$ Mill, John Stuart "On Liberty" and Other Writings (Cambridge University Press, 1989).

11 Shelley Burtt, "The Politics of Virtue Today: A Critique and a Proposal», American Political Science Review 87, n. 2 (1993): 360; Shelley Burtt, "The Good Citizen's Psyche: On the Psychology of Civic Virtue», Polity 23, n. ${ }^{\circ} 1(1990): 23$.
} 
mandas de igualdad de derechos, siendo el más sobresaliente el derecho al sufragio, pero no el único ${ }^{12}$. El derecho a la propiedad privada o a un igual trato ante la ley, o más contemporáneamente el acceso igualitario a los puestos de trabajo, en algunos casos incluso si esta demanda de igualdad de acceso implica la demanda de "cuotas" mediante políticas de acción afirmativa, una demanda que parece oponerse a la tradicional reticencia liberal a la intervención estatal. Pero también ha llamado la atención sobre lo nocivo que puede resultar un Estado paternalista en sociedades donde existe una arraigada desigualdad de género, donde las leyes son empleadas para limitar las opciones de las mujeres.

Resistir a la arbitrariedad de los fines del Estado parece un objetivo irrenunciable, más aún para las mujeres, cuyo cuerpo siempre ha sido materia de decisión para el poder político ${ }^{13}$. Drucilla Cornell propone el concepto "dominio imaginario", como una suerte de espacio protegido frente a las intervenciones, tanto del Estado, como de la sociedad. Un espacio que la autora define como aquel en que, en tanto criaturas sexuadas, podemos evaluar y representarnos quiénes somos, imaginar una realidad distinta de aquella en la que actualmente vivimos, un espacio imprescindible para la utopía y, por ende, para cualquier política transformadora: "no queremos que el estado supervise el contenido de nuestro dominio imaginario" ${ }^{14}$. El antiperfeccionismo feminista parece una herramienta necesaria para protegernos frente a políticas conservadoras, garantizar un ámbito de privacidad que haga posible la autodeterminación. Aunque dicho ámbito de no interferencia pueda resultar un arma de doble filo muchas veces.

Muchas de las demandas y logros del feminismo liberal, no obstante, cuestionan conceptos cardinales de la tradición a la que pertenecen, no solo el de la no-intervención estatal (y con ello los límites del principio del daño), sino el de la equivalencia entre autonomía y deseos conscientes del agente, al cuestionar la aparente felicidad de las mujeres que se conforman con ocupar los tradicionales roles de esposas y madres. ${ }^{15}$

En un brillante análisis sobre la formación de deseos y creencias en cuanto motivos para la acción, Anita Superson ${ }^{16}$, identifica cinco características de lo que ella denomina "deseos deformados". Este análisis pone de manifiesto que los deseos y las preferencias no son completamente espontáneas, sino que son producto del entorno en el que nos desarrollamos y, en una sociedad injusta, serán el producto

\footnotetext{
${ }^{12}$ Hagar Kotef, "On Abstractness: First Wave Liberal Feminism and the Construction of the Abstract Woman", Feminist Studies: FS. 21, n. 3 (2009): 495-522.

13 Cornell, Drucilla, At the Heart of Freedom (Princeton, N.J: Princeton University Press, 1998).

${ }_{14}$ Cornell, Drucilla, At the Heart of Freedom (Princeton, N.J: Princeton University Press, 1998).

${ }^{15}$ Ver por ejemplo Friedan, Betty, The Feminine Mystique (New York: W. W. Norton \& Company, 2001).

${ }^{16}$ Anita M Superson, «Deformed Desires and Informed Desire Tests», Hypatia 20, n. 4 (2000): 109-26.
} 
de las relaciones de dominación existentes, deseos que contribuyen a su vez a que la dominación se reproduzca y benefician a los grupos que salen gananciosos de la dominación. Los deseos deformados que comenta Superson, son producto del autoengaño y son, por lo mismo, difíciles de erradicar desde una intervención que se plantee desde el "principio del dańo" milliano, es decir, desde el cuidado de la libertad individual hasta donde no dańa a otros. En un contexto de opresión el sujeto deviene otro para sí mismo. Pero afirmar esto implica ponerse en el límite externo de la moral liberal.

La referencia a deseos deformados, rompe entonces con el dogma liberal de la transparencia de las preferencias, y cuestiona por ende la idoneidad de una fundamentación de la moral y la legitimidad política en el mero interés propio de los agentes, o en su consentimiento, y por ende, la posibilidad efectiva de una emancipación de las mujeres en clave liberal

Parte de la impotencia del feminismo liberal para hacerse cargo de esta tarea, se debe a su compromiso con la neutralidad axiológica que, aunque actúa como profilaxis frente a los valores del conservadurismo moral, le impide poner en tela de juicio los valores impulsados por el mercado, y limitarse, por el contrario, a demandar el acceso igualitario de las mujeres y de las minorías étnicas a dicha sociedad, sin proponerse transformar la cualidad mercantil de dichas relaciones, que han sido hechas a la medida de los varones, creando una complicidad entre el patriarcado y el capitalismo de libre mercado. ${ }^{17}$ No deja espacio para transformar el orden existente, sino solo para hacerlo accesible a más individuos. Dicho de otro modo, las reclamaciones del feminismo liberal son en último término reclamaciones de acceso al libre mercado en igualdad de condiciones, aunque ello demande medidas reparatorias provisionales, como la acción afirmativa. Desde la perspectiva liberal de la inclusión, la incorporación de las mujeres blancas al mercado de trabajo dominado por hombres, va de la mano con la necesidad de que ese cuidado sea realizado por otras, muchas veces mujeres "de color" y pobres, por lo que la emancipación de unas en el mercado, va de la mano con la opresión de otras bajo condiciones laborales precarias.

El individualismo abstracto y la somatofobia, elementos ambos que Jaggar señala como característicos de la concepción liberal de la naturaleza humana, le impiden al feminismo liberal ir todo lo lejos que su objetivo emancipador requeriría. Jaggar ${ }^{18}$ afirmará que el feminismo liberal no es una base filosófica adecuada para la liberación de las mujeres. El individualismo abstracto hace referencia a la idea de que

\footnotetext{
${ }_{17}$ Federici, Silvia, Revolución en punto cero: trabajo doméstico, reproducción y luchas feministas (Madrid: Traficantes de Sueños, 2013).

18 Jaggar, Alison M, Feminist Politics and Human Nature (Totowa, N.J.: Rowman \& Allanheld, 1983).
} 
los individuos pueden ser separados de sus contextos sociales, y es finalmente un concepto normativo respecto de lo que un adecuado uso de la razón debería ser: la razón universal no es sensible al contexto. Si bien las feministas liberales han cuestionado en parte esto al hacer aparecer el sexo como determinante de las relaciones sociales y del acceso a los derechos, la aspiración final es la de hacer que las diferencias sexuales se vuelvan irrelevantes, incluso aquellas atribuibles exclusivamente a la biología, como la capacidad de dar a luz. No es difícil situar aquí la somatofobia. Con todo, la somatofobia termina alimentando la división capitalista del trabajo sexual, en tanto el trabajo asociado al cuerpo, sobre todo aquellas típicamente feminizadas, o realizadas por migrantes pobres -como las labores de cuidados- tienen una valoración social y económica inferior ${ }^{19}$.

La comprensión liberal del espacio público se hace insuficiente para una teoría y una práctica políticas que apuntan a identificar formas de dominación en el cotidiano. Para el liberalismo y su delimitación de la familia como esfera de no intervención, el ámbito de las relaciones íntimas no puede ser comprendido como uno donde sea posible la dominación, como tampoco la acción política de resistencia a esta. Al sujeto político del modelo liberal le corresponde más bien ser un evaluador racional ${ }^{20}$ de las decisiones políticas que son tomadas en otro lado, es insuficiente como marco de comprensión para la política que se construye desde los movimientos sociales hoy en día, como lo que buscamos proponer aquí a través del concepto de ciudadanía feminista, sin desconocer que lo fuera para las revoluciones democráticas del siglo XIX, en tanto que estas eran precisamente revoluciones antiabsolutistas que se movían en un espacio político bien definido: el del poder político institucional primero, y el de la sociedad de masas que adviene con la democracia, después. La meta política de las revoluciones democráticas era el establecimiento de un ámbito de exclusión del poder político o del juicio de la sociedad. La ciudadanía feminista, en cambio, no persigue una mera ampliación del derecho político, sino un giro radical respecto de quién hemos de considerar el sujeto político.

La propuesta de un modelo feminista de ciudadanía, no se trataría de una ciudadanía diferenciada para varones y mujeres, sino de rescatar los conceptos que se ponen en juego en el movimiento feminista, la particular forma de entender la política que emerge desde ahí y las virtudes y prácticas asociadas a ella. Mary Dietz $^{21}$, en su rechazo de los argumentos maternalistas, apuntará la especificidad de lo público como constitutivo de la identidad dada en la ciudadanía democrática. Más que buscar el modelo de ciudadanía en el cuidado maternal, Dietz propone la

\footnotetext{
${ }_{19}$ Young, Iris Marion, Justice and the Politics of Difference (Princeton University Press, 1990).

${ }^{20}$ Macedo, Liberal Virtues, 240.

${ }^{21}$ Dietz, M, "Citizenship with a feminist face: The problem with maternal thinking.», Political Theory, 1985.
} 
tradición republicana como lenguaje político alternativo para pensar una ciudadanía propiamente feminista.

Dietz es crítica tanto del rechazo de la categoría de ciudadanía por parte de las feministas marxistas, como de la que es propia de las maternalistas quienes reniegan de los valores políticos tradicionales, por considerarlos fríos y patriarcales. Elshtain ${ }^{22}$ es el principal blanco de sus críticas. Para Dietz, las feministas deberían reivindicar no valores de una femineidad esencial, reducida al ámbito privado, sino valores propiamente políticos:

Lo que eso exige, entre otras cosas, es una disposición a percibir la política de una manera que no la perciben los liberales ni las maternalistas: como una actividad humana que no es por necesidad ni desde el punto de vista histórico, reducible a gobierno representativo o 'el arrogante reino masculino y público". ${ }^{23}$

Dietz propone una adhesión feminista a los valores del republicanismo democrático. Sin embargo, el republicanismo ha sido tradicionalmente hostil a las mujeres, cuya exclusión del espacio público se ha justificado con diferentes argumentos, aunque todos apuntan en una dirección similar: la incapacidad natural de las mujeres para desempeñarse virtuosamente en el espacio público, es decir, para dejar de lado el interés particular, en favor del interés general, el de la república. En las siguientes páginas intentaré probar que el republicanismo, al menos en su forma clásica, no ofrece una concepción de la ciudadanía compatible con los objetivos feministas, más allá de las circunstancias particulares de los autores y la autora que expondré, se trata de los valores en juego -precisamente lo que Dietz defiende- lo que resulta incompatible con la ciudadanía feminista que aquí proponemos.

Comenzaré este recorrido entonces con Rousseau, quien es usualmente señalado como un pensador de la emancipación, por lo que, a primera vista resulta inverosímil suponer que ha conservado a las mujeres en la sujeción, mostrando el camino de una emancipación únicamente masculina.

La misoginia rousseauniana ha sido notada por Pateman en el artículo de 1980 El desorden de las mujeres: mujeres, amor y el sentido de la justicia ${ }^{24}$. Tal como lo aclara la autora al principio del texto, "El desorden de las mujeres" hace referencia a una cita del mismo Rousseau en la famosa Carta a D'Alembert ${ }^{25}$, donde señala que

\footnotetext{
22 Jean Bethke Elshtain, Public Man, Private Woman: Women in Social and Political Thought (Princeton University Press, 1981).

23 Dietz, Mary, "Context is all: feminism and theories of citizenship», en Dimensions of radical democracy: pluralism, citizenship, community, ed. Chantal Mouffe, 2nd impr, Phronesis (London [etc.]: Verso, 1995), 75.

${ }^{24}$ Pateman, Carole, "The Disorder of Women”: Women, Love, and the Sense of Justice», Ethics 91, n. ${ }^{\circ} 1$ (1980): 20-34.

25 Rousseau, Jean Jacques, Carta a D’Alembert (Lom Ediciones, 1996).
} 
la principal causa de decadencia de un pueblo, no es su tendencia a los vicios como el vino, sino "el desorden de las mujeres". La condena del desorden en ellas nos hace suponer la existencia de un deber de orden, cuyo incumplimiento redundaría en la perdición del pueblo.

La condena de las mujeres como inductoras del vicio es tan antigua como el relato bíblico del Génesis, no obstante, el "desorden de las mujeres" al que alude Rousseau, sería uno de una índole más compleja que la mera incapacidad femenina de reprimir el impulso sexual ${ }^{26}$.

El rol perturbador de las mujeres en la sociedad es analizado junto al del vino. El ginebrino se muestra más permisivo con este último, pues el consumo de vino solo podría destruir a un pueblo que ya es vicioso, no ser un vicio en sí mismo. El desorden de las mujeres en cambio, es siempre peligroso y no remite únicamente al desorden propio de la vida licenciosa de las actrices, asunto recurrente en la carta -dado que el tema del que discute con D'Alembert es lo nocivo de los espectáculos teatrales- sino el afeminamiento de las costumbres. El amor y la pasión que portan las mujeres son la perdición de un pueblo. Si las mujeres dejan de someter su naturaleza pasional mediante la modestia que el buen Rousseau prescribe, entonces el pueblo completo sucumbe. El amor, como pasión, aunque pueda ser virtuoso, es una virtud de segundo orden, peligrosa, en tanto que es difícil de domar ${ }^{27}$. El amor, cuando es una pasión ordenada, es un buen complemento de las virtudes; mas, cuando este se presenta de manera excesiva y desordenada, como parece inevitable para Rousseau, hace que los hombres se olviden de sus verdaderos deberes. Las mujeres, tal era la convicción de Rousseau, no tenían la misma capacidad para cumplir con los deberes cívicos que los varones, por ello su lugar, más que el espacio público, era el espacio de lo doméstico, espacio gobernado por la ley del amor. Pero el amor, que no podía ver la luz de lo público, tampoco podía desordenarse en lo privado. La mujer, nos recuerda Pateman, debía hacerse cargo del orden y la limpieza en el espacio doméstico. La fijación de Sofía, la compañera de Emilio, con el orden, le restituye la pureza perdida por el pecado original de nacer mujer. El desorden del amor es la perdición, personal y colectiva. Nos lo recuerda la trágica muerte de Julie en La Nouvelle Héloïse. ${ }^{28}$ Este temor del desorden de lo privado, entendido como desorden sexual, fue también preocupación de la ortodoxia comunista. Nos lo recuerda Carla Lonzi en su manifiesto Escupamos sobre Hegel ${ }^{29}$, donde citará las recomendaciones de Lenin a Clara Zetkin e Inés Armand, para dirigir la lucha de

26 Rousseau, 203.

27 Rousseau, 212.

28 Rousseau, Jean Jacques, Julia, o la nueva Eloisa, Madrid (Ediciones AKAL, 2007).

29 Lonzi, Carla, Escupamos sobre Hegel (Barcelona: Anagrama, 1981). 
las mujeres proletarias en la dirección correcta. Particularmente a esta última le habría hecho reparos sobre la inclusión del "amor libre" en el opúsculo para las trabajadoras, que preparaba. La respuesta al matrimonio sin amor de la burguesía no era el amor libre, sino el matrimonio civil proletario. De nuevo la llamada al orden, incluso en lo íntimo, pues ellos siempre supieron que el germen de la política feminista se encontraba ahí.

El rechazo de las costumbres burguesas es también ampliamente tematizado por Rousseau, de ahí que la caracterización de la educación de Sofía, destinada a ser la compañera de Emilio, su complemento, haya estado orientado a mantener ese orden y castidad, que si bien no le venían naturalmente dados, debían serle inculcados por el bien de la comunidad. La moral (moral sexual en este caso) y la política, están profundamente entrelazadas para Rousseau. Sabemos que la educación de Sofía ha sido uno de los objetos predilectos de las críticas a Rousseau; sin embargo existirían voces disidentes en torno a la misoginia rousseauniana que es preciso escuchar. De acuerdo con Mira Morgenstern ${ }^{30}$, en su revisión de la recepción de Rousseau por el feminismo, no sería del todo apropiado afirmar la misoginia del autor, pues las afirmaciones que fundamentan esta interpretación estarían contenidas únicamente en sus novelas (el Emilio y La Nouvelle Héloïse) y del todo ausentes en sus tratados políticos, por lo que derivar consecuencias políticas de ellos podría parecer al menos parcial. Sin embargo la evidencia de la Carta a D'Alembert que hemos revisado de la mano de Pateman, deja poco lugar a dudas y la misoginia que se deja leer aquí, tiene un costo importante para el proyecto emancipatorio rousseauniano. Las mujeres no logran romper las cadenas en el contrato social rousseauniano, no logran la libertad civil que debía proveer la ciudadanía. ${ }^{31}$

Difícilmente la ciudadanía feminista podría ver un aliado en el republicanismo. Una vez más, el desorden, la "ironía de la comunidad", dirá Hegel (2000) pero esta no idoneidad de las mujeres, las mismas que en el hogar deben hacerse cargo de la formación de los aguerridos ciudadanos republicanos, es más que un rasgo propio de las teorías de Rousseau y Hegel; es, con toda seguridad, el corolario de una particular construcción de la virtud como sacrificio, como un valor y una fortaleza que son definidos a partir de la psique del guerrero, del ciudadano espartano.

La crítica feminista a Hegel también está mediada por la literatura, pero esta vez no se trata de una construcción ad hoc, como Sofía o Julie, sino en la interpretación que el alemán hace de la Antígona de Sófocles, a quien usa como ejemplo de la imposibilidad femenina para adecuarse a la universalidad. Mientras los varones se

\footnotetext{
30 Morgenstern, Mira, «Rousseau and modern feminism», Pensèe Libre 5 (1995): 154-67.

31 Cobo, Rosa, Fundamentos Del Patriarcado Moderno, Jean Jacques Rousseau, Feminismos 23 (Madrid: Cátedra, 1995).
} 
encuentran más cercanos a la ley divina, y por ende a la universalidad, las mujeres están más cerca de la ley humana, la ley propia de los penates o espíritus familiares. Ese apego a la particularidad, las hace peligrosas en el espacio público y justifica con creces su exclusión. ${ }^{32}$

Hegel, sin lugar a mayores dudas, reconoce la oposición entre la familia y la comunidad. El elemento femenino, la femineidad, en cuanto vencido, se convierte en el enemigo interior de la comunidad, y por ello será el elemento que la tensione constantemente, pues ha sido oprimido por ella, la eterna ironía. El desorden aparece una vez más del lado del principio femenino que se niega a disolverse completamente en la ley de la universalidad y quisiera ver todo el Estado disuelto en la individualidad de los miembros de la familia. En su Filosofía del derecho, ahondará en lo escrito previamente en la Fenomenología sobre el origen de la ley del Estado, volverá a citar a Antígona, como la más sublime expresión de la tragedia que constituye el choque entre la ley humana y la ley divina, entre la objetividad y el deseo de la universalidad, propias de la virilidad y la subjetividad y el sentimentalismo, asociados a la feminidad. ${ }^{33}$

Durante el siglo XX, la retórica republicana es brillantemente retomada por Hannah Arendt, quien exaltará las virtudes del espacio público clásico, frente a la entrada de la sociedad en la política, propia del contexto contemporáneo. Pero el modelo de espacio público que Arendt reivindica, se caracteriza por la exclusión de las mujeres, los esclavos y los extranjeros. La distinción conceptual de Arendt entre lo público y lo privado, tiene consecuencias normativas indeseables, las que Seyla Benhabib en Models of Public Space hace notar desde el cuestionamiento a la denominada antimodernidad de Hannah Arendt ${ }^{34}$. Dicho brevemente: la exaltación de la esfera pública republicana como espacio público agonístico es, a su vez, una exaltación de la exclusión simbólica y fáctica de las mujeres.

A la interpretación del espacio público agonístico, Benhabib opone el espacio público asociacional. Este espacio, emancipado de la referencia topográfica, emerge donde sea y cuando sea que los hombres (y las mujeres, habría que agregar) actúan concertadamente con miras a un fin compartido. Las demandas de los grupos que la comprensión agonística del espacio público excluía sistemáticamente, son, bajo el modelo asociacional, susceptibles de ser comprendidas como legítimas demandas de justicia que ocupan el espacio público. La primera concepción del espacio públi-

\footnotetext{
${ }^{32}$ Hegel, Georg Wilhelm Friedrich, Fenomenologia Del Espiritu, trad. Antonio Gómez Ramos (Madrid: Abada, 2010), 563

${ }^{33}$ Hegel, Georg Wilhelm Friedrich, Rasgos fundamentales de la filosofia del derecho. O compendio de derecho natural $y$ deciencia del estado. (Madrid: Biblioteca Nueva, 2000), 238, 239.

${ }^{34}$ Benhabib, Seyla, «Models of Public Space: Hannah Arendt, the Liberal Tradition, and Jürgen Habermas», en Habermas and the Public Sphere, ed. Craig J. Calhoun (MIT Press, 1992), 75.
} 
co como topos del agon y de la aparición en sentido fuerte frente al otro, delimitaba desde la teoría la agenda política, como aquello que puede ser expuesto a los otros. Para Benhabib lo que importa en el discurso público político no es el contenido previamente determinado de los temas que deberá abordar una agenda política, sino la forma en que éste debe tener lugar. Esta forma está dada por la exclusión de la violencia en el espacio público.

La maniobra argumentativa de Benhabib consiste entonces en desechar el concepto más rígido de publicidad, para rescatar aquel otro concepto más flexible, más poroso a las demandas de justicia que configuran una sociedad democrática. Con todo, podemos introducir cierta sospecha sobre el intento de diferenciar completamente los medios violentos de los medios democráticos, cuestión que precisamente pretendemos criticar a través de la noción de ciudadanía feminista. Habría que preguntarse nuevamente cuál es el lugar de la violencia dentro de una democracia cuyas condiciones de acceso tanto al poder económico, como a la influencia política (más interrelacionados de lo que quisiéramos), dejan a muchas y muchos afuera. Agnes Heller ${ }^{35}$ añadirá que, pese que la comunicación libre de dominación es el objetivo de la emancipación, dado que las condiciones ideales del discurso enunciadas por Habermas difieren considerablemente de las condiciones efectivas de la vida en nuestras democracias, la violencia actuaría, entonces, como una condición pre-discursiva del discurso político, abriendo un espacio hasta entonces cerrado para ciertos grupos excluidos. No se trata, por supuesto, de afirmar que el uso de la violencia pueda ser legitimado en atención a los fines que persiga, este es un camino peligroso. De lo que se trata aquí es de asumir que la violencia está presente en las estrategias políticas y que para muchos grupos marginados estructuralmente del espacio público, y de sus formas tradicionales de representación, puede ser el único camino disponible. ${ }^{36}$

Por su parte Hannah Pitkin, también someterá a crítica la concepción agonal del espacio público, no por lo limitado del público que puede dar cuenta de las hazañas que configuran lo agonal, sino por la banalidad de dicha ocupación del espacio público. La justicia, destaca Pitkin, está ausente en la teoría política de Arendt y es por ello que las demandas provenientes de la esfera de reproducción de la vida, le parecen indignas de entrar en la lógica que considera propia de la política. La emergencia de lo social, que es fundamentalmente la cuestión de la pobreza, encuentra su solución no en el espacio público de la acción política, sino más bien en la téc-

\footnotetext{
35 Agnes Heller, Crítica de la ilustración: las antinomias morales de la razón (Ediciones Península, 1999).

36 Una crítica a las condiciones ideales del discurso y en general a la idea de consenso racional en Habermas puede ser encontrada en Javier Muguerza, «Habermas en el "reino de los fines”. (Variaciones sobre un tema kantiano)», en Esplendor y miseria de la ética kantiana, ed. Esperanza Guisán (Anthropos Editorial, 1988), 97-139.
} 
nica. Arendt no ve cómo la mera técnica es insuficiente para resolver un problema que es multidimensional. Cambiar la estructura de la distribución de la riqueza, por ejemplo, no se logra únicamente diseńando un sistema tributario que disminuya la brecha entre quienes ganan más y quienes ganan menos, el mero diseño no garantiza su aceptación por parte de los legisladores, ni de las corporaciones, ni de las ciudadanas y ciudadanos de a pie. Es una cuestión de justicia.

Pitkin no titubea en señalar las consecuencias nefastas de un espacio público concebido solo para la inmortalidad y que pretende condenar las faenas de la supervivencia, a la oscuridad. La justicia para Pitkin, consiste precisamente en aquello que Arendt teme, en aquello que los honorables varones de la tradición republicana también temen: el desorden de las mujeres. Pero no solo de las mujeres; el desorden de lo privado en tanto que inquietud de aquello que debía estar caracterizado por la mera pasividad, por la circularidad de los procesos de reproducción de la vida.

Contra la lectura lineal del desarrollo de los derechos que ha ofrecido la perspectiva marshalliana, la historia de los derechos sociales, que son la entrada de la esfera de la reproducción a lo político, ha sido la historia de la politización de ámbitos otrora privados, la historia de la identificación de una estructura opresiva común tras las carencias particulares. La política dirá Pitkin, es ese constante paso de lo privado a lo público, que impone en nosotros la obligación de modular nuestras exigencias en el lenguaje de lo público, que permite articular las demandas de justicia como tales.

Anne Phillips explora las posibilidades de una alianza entre el feminismo y el republicanismo, llamando la atención sobre las dificultades que esta conlleva. Para Phillips la tradicional concepción del espacio público en clave masculina y la consecuente devaluación de las actividades femeninas como no-políticas, son obstáculos importantes para el éxito de dicha alianza. Cifrará sus esperanzas, no obstante, en el énfasis de las ideas republicanas en la no-dominación, un ideal fructífero para la emancipación femenina. Para Phillips un feminismo republicano debería proponerse la revalorización del espacio público, no mediante el intento de devolverle el aura que Arendt echa en falta, sino todo lo contrario, de valorizar las diferentes formas que tiene la política en nuestros días:

Las feministas han notado indicios de actividad política en lugares inesperados -incluso clandestinos, en algunos casos-y aunque esto lleve a veces a una lectura demasiado optimista de la política contemporánea, es un importante correctivo a los escenarios más apocalípticos que proyectan procesos de decadencia histórica. ${ }^{37}$

${ }_{37}$ Phillips, Anne, «Feminism and Republicanism: Is This a Plausible Alliance?», Journal of Political Philosophy 8, n. ${ }^{\circ} 2$ (1 de junio de 2000): 292. 
El feminismo y el republicanismo pueden construir una alianza en la que el feminismo no sea la víctima sacrificial, a condición de que este renuncie a su tradicional concepción de la esfera pública y de la virtud cívica, en tanto que eminentemente masculina, que hemos analizado críticamente aquí. Esta transformación en el ideal de publicidad haría al republicanismo más sensible a las nuevas formas de organización y expresión política, en tanto que resistencias a las múltiples formas de violencia que el patriarcado y el capital ejercen cotidianamente.

El concepto de ciudadanía feminista puede ser una categoría fructífera de análisis en tanto permite entender nuevas formas de organización y acción desde los movimientos sociales, que quedan fuera de la grilla de la publicidad y participación de la clave republicana tradicional. 


\section{REFERENCIAS BibLIOGRÁficas}

Benhabib, Seyla. «Models of Public Space: Hannah Arendt, the Liberal Tradition, and Jürgen Habermas». En Habermas and the Public Sphere, editado por Craig J. Calhoun. MIT Press, 1992.

Berlin, Isaiah. Cuatro Ensayos Sobre La Libertad. El libro universitario. Madrid: Alianza, 1998.

Burtt, Shelley. «The Good Citizen's Psyche: On the Psychology of Civic Virtue». Polity 23, n. 1 (1990): 23. https://doi.org/10.2307/3235141

— «The Politics of Virtue Today: A Critique and a Proposal». American Political Science Review 87, n. ${ }^{\circ}$ (1993): 360. https://doi.org/10.2307/2939046

Cobo, Rosa. Fundamentos Del Patriarcado Moderno, Jean Jacques Rousseau. Feminismos 23. Madrid: Cátedra, 1995.

Cornell, Drucilla. At the Heart of Freedom. Princeton, N.J: Princeton University Press, 1998. https://doi.org/10.1515/9781400822553.toc

Dietz, M. «Citizenship with a feminist face: The problem with maternal thinking.» Political Theory, 1985. https://doi.org/10.1177/0090591785013001003

Dietz, Mary. "Context is all: feminism and theories of citizenship». En Dimensions of radical democracy: pluralism, citizenship, community, editado por Chantal Mouffe, 2nd impr. Phronesis. London [etc.]: Verso, 1995.

Elshtain, Jean Bethke. Public Man, Private Woman: Women in Social and Political Thought. Princeton University Press, 1981.

Federici, Silvia. Revolución en punto cero: trabajo doméstico, reproducción y luchas feministas. Madrid: Traficantes de Sueños, 2013.

Friedan, Betty. The Feminine Mystique. New York: W. W. Norton \& Company, 2001.

Heater, Derek Benjamin. Ciudadania: una breve historia. Madrid: Alianza, 2007.

Hegel, Georg Wilhelm Friedrich. Fenomenología Del Espiritu. Traducido por Antonio Gómez Ramos. Madrid: Abada, 2010.

- Rasgos fundamentales de la filosofía del derecho. O compendio de derecho natural $y$ deciencia del estado. Madrid: Biblioteca Nueva, 2000.

Heller, Agnes. Crítica de la ilustración: las antinomias morales de la razón. Ediciones Península, 1999. 
Hobbes, Thomas. Hobbes: On the Citizen. Cambridge: Cambridge University Press, 1998.

Jaggar, Alison M. Feminist Politics and Human Nature. Totowa, N.J.: Rowman \& Allanheld, 1983.

Kotef, Hagar. «On Abstractness: First Wave Liberal Feminism and the Construction of the Abstract Woman». Feminist Studies : FS. 21, n. 3 (2009): 495-522.

Lonzi, Carla. Escupamos sobre Hegel. Barcelona: Anagrama, 1981.

Macedo, Stephen. Liberal Virtues: Citizenship, Virtue, and Community in Liberal Constitutionalism. Oxford: Clarendon Press, 1992.

Mill, John Stuart. J. S. Mill: "On Liberty» and Other Writings. Cambridge University Press, 1989.

Miraftab, Faranak. «Invited and Invented Spaces of Participation: Neoliberal Citizenship and Feminists' Expanded Notion of Politics». Wagadu 1, n. ${ }^{\circ}$ Spring 2004: 1-7.

Morgenstern, Mira. «Rousseau and modern feminism». Pensèe Libre 5 (1995): 154-67.

Muguerza, Javier. "Habermas en el "reino de los fines". (Variaciones sobre un tema kantiano)». En Esplendor y miseria de la ética kantiana, editado por Esperanza Guisán, 97-139. Anthropos Editorial, 1988.

Pateman, Carole. "'The Disorder of Women": Women, Love, and the Sense of Justice». Ethics 91, n. ${ }^{\circ} 1$ (1980): 20-34. https://doi.org/10.1086/292200

- The Sexual Contract. Stanford University Press, 1988.

Phillips, Anne. «Feminism and Republicanism: Is This a Plausible Alliance?» Journal of Political Philosophy 8, n. ${ }^{\circ} 2$ (1 de junio de 2000): 279-93. https://doi. org/10.1111/1467-9760.00103

Rousseau, Jean-Jacques. Carta a D'Alembert. Lom Ediciones, 1996.

- Julia, o la nueva Eloísa. Madrid. Ediciones AKAL, 2007.

Superson, Anita M. «Deformed Desires and Informed Desire Tests». hyp Hypatia 20, n. ${ }^{\circ} 4$ (2000): 109-26. https://doi.org/10.1111/j.1527-2001.2005.tb00539.x

Young, Iris Marion. Justice and the Politics of Difference. Princeton University Press, 1990. 
